\title{
Creating Synthesis: Art and New Technology as Unseparatedness
}

\author{
Dami Kim \\ Paris College of Art \\ 128 rue Brancion 75015 Paris France \\ dami7060@gmail.com
}

\begin{abstract}
This paper aims at finding how to create a synthesis of art and new technology. Referring to Hegelian Dialectics, synthesis means art that is not governed by any separation, polarization or further hierarchy in relation to new technology. Systems Art suggested by Jack Burnham in the late 1960s is failed to be such a synthesis, as well as was failed art in those days. Systems art and new technology are in a linear or separable relation since the art is mere educational to inform of the technological system. As its counterpart this paper suggests one way to create a synthesis: unseparatedness of technophilia and technophobia as cultural dualism. It describes Maya Deren's creation in the post-WWII environment through her own writings. Deren embraced science's systematic process as a source of development while disappointed at the results science contributed to during the war. This unseparated technophile and technophobic mind pushed her towards developing a synthesis, inhering transcendence and therefore evolution of the relation between new technology and human.
\end{abstract}

Synthesis of Art and Technology, New Technology, Systems Art, Video-dance, Technological Art, Contemporary Art, Technophilia versus Technophobia

\section{INTRODUCTION}

Futurism, Surrealism and Technological Utopianism in the $20^{\text {th }}$ century dealt with new technology as a main question in the arts not just as a tool. Today this tendency returns due to the unprecedented technological influences on human. As much as current society gives power to technocrats, artists become actively focused on new technology in their creation. This paper is addressed particularly to criticize its over-focused cases of superficial uses and blind pursuit of new technology in creating art.

Criticizing it, this paper seeks for how to create a synthesis of art and new technology. Hegel's idea of synthesis is understood as follows: "any 'ism' which has a polar opposite, or is a special viewpoint leaving 'the rest' to itself - must be criticized by the logic of philosophical thought whose problem is reality as such, the "World-itself."' Mueller (1958, p.411) Based on this, here proposes synthesis as art that does not lean to any separation, polarization or further hierarchy in relation to new technology.

Firstly this paper looks at Systems Art suggested by Jack Burnham, an art theorist, in the late 1960s. It was failed technophile art in those days.
Secondly Hegelian Dialectics is studied to explain this failure specifically. At last the creation of Maya Deren, an experimental filmmaker and a dancer, is suggested corresponding to Hegel's notion of synthesis. It was in the dilution of the division between technophilia and technophobia in the 1940s.

This paper's methodology is looking the present by reflecting it in the preceding cases. It centers on each thought and emotion the individuals had rather than historical perfection. Adaption or transformation of the cases could be powerful for today's artists to imagine the next.

\section{FAILURE OF SYSTEMS ART}

Systems Art was suggested by Burnham between the end of Technological Utopianism and the beginning of Postmodernism. The theorist insisted in Systems A esthetics (1968) that artists should communicate about new technology to inform society of the technological process and result, which were together defined as a system. It was technophile in his own words, and the concept of system was widely used in natural sciences and cybernetics. 
Hans Haacke was a representative of the artists working with Burnham. In Photoelectric $V$ iewercontrolled Coordinate S ystem (1968) by Haacke, Systems Art's aesthetics is evident. Lights installed in a room react to audiences' movements, changing space. Not only audiences experience the mechanisms of control, but also it does not have fixed boundaries differently from art of an object (Burnham 1968).

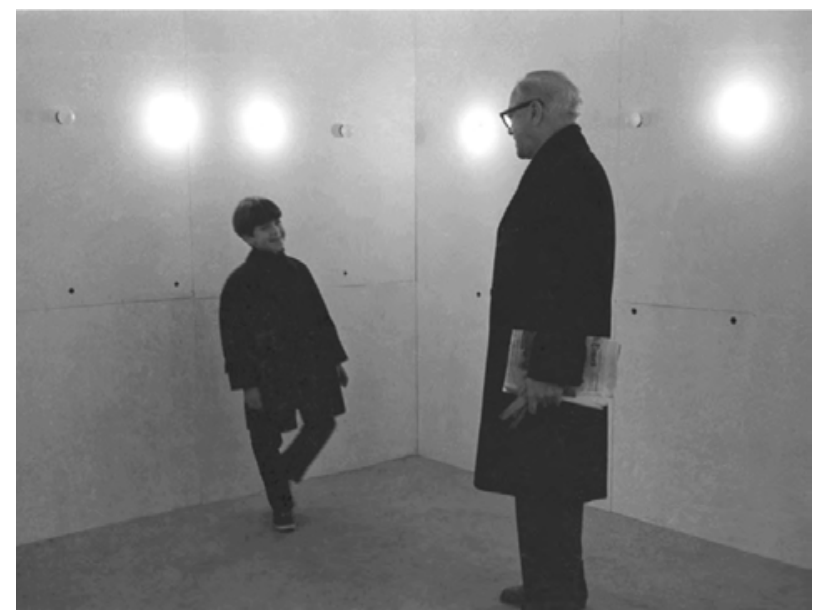

Figure 1: Haacke, Hans. Photoelectric Viewer-controlled Coordinate System, 1968

However, Systems Art was soon rejected by artists and theorists including Burnham himself (Burnham 1980). ${ }^{1}$ Curating an exhibition Software (1970), he found technology in each artwork was not stable enough to be exhibited. 'Pop technology' and art in favour of the armed forces were also marked by 'humanistic' critics. ${ }^{2}$ Most importantly, they were hardly persuaded by the role of art as a learning medium of the technological system. Art should not be mere educational.

\section{HEGELIAN DIALECTICS}

Systems Art was failed in the art scene at that time. By Hegelian Dialectics this paper attributes this failure to its impossibility to be a synthesis.

A synthesis of two entities are not sum of the two abstracted from their own categories. There two entities exist in a relation of negation or contradiction, behaving as one unity otherwise the notion of negation or contradiction is not valid. This unseparated unity of two contradictory entities essentially involves inward unrest, flying into transcendence (Hegel 1954).

\footnotetext{
${ }^{1}$ Burnham had strongly criticized his own view, but it should be noted that scholars today have re-evaluated the theory as insightful $t$ in terms of understanding system. It inspired Relational Aesthetics developed by Nicolas Bourriaud (Bourriaud 1997).

${ }^{2}$ These are not the reasons for Systems Art's failure to be a synthesis but mentioned here to show the common issues of technological art in the 1960s and today.
}

In Systems Art art and new technology are not negated by each other. Art stays in its own role to communicate about society, and new technology is intact with its original functions and characteristics. Such linear interaction cannot result in evolution.

Then what could be grasped as two contradictory entities regarding art and new technology? This paper suggests the cultural dualism of technophilia and technophobia as these entities. They are contradictory within one unity named culture. The following chapter examines this idea by a case study on Maya Deren, an experimental filmmaker and a dancer. Her creation was influenced by her embrace of science in the post-WWII environment.

\section{MAYA DEREN'S SYNTHESIS}

Maya Deren might rarely appear in the technological history of art. This paper looks at her creation with new eyes by focusing on her acquaintance with scientific knowledge along artistic aptitude. This chapter covers from the artist's biographical and historical backgrounds to how her synthesis was created through her unseparated technophile and technophobic mind. The latter is demonstrated by delving into her personal notebook.

\subsection{Background}

Deren was equipped with the capacities to be conscious of as well as attentive to the scientific development and its effects on human. Since her early ages she had been exposed to the sciences. Her father was a psychologist and physician, and she had studied political science in her first college. This background allowed her to comprehend the principles of science and technological operations.

Like surrealist artists Deren was disappointed at the results science contributed to during the war and post-WWII periods. Instead of rejecting science, however, she focused on its procedure which had brought about its own achievements. Deren further compared it with that of art in her time, and criticized its procedure:

"The impulse behind my insistent concern with the triumphant achievements of science is most elemental: I believe simply that an analysis of any of man's achievements may reveal basic principles of methodology which, properly adjusted to the immediate conditions of other problems, $[\ldots]$.

[...] the role of the artist has degenerated into a basic passivity. He functions as an often inaccurate barometer, scaled in emotional degrees, [...]"

Deren (1946, p.21)

As such Deren embraced science in the post-WWII environment. Being under both technophilia and 
technophobia, the artist was constantly bothered and pushed in between art, science and technology.

\subsection{Creating Synthesis}

This section demonstrates how her embrace of science had been manifested in the creation of her artistic language. It was mostly reflected in its developing process. Deren borrowed systematic approach from science, observing and comparing the human body and camera, a machine. Secondly she treated a camera like her 'extended' body. Here explains the two manifestation through the artist's notebook, and draws parallels between the notes and one of her film A Study in Choreography for Camera (1945).

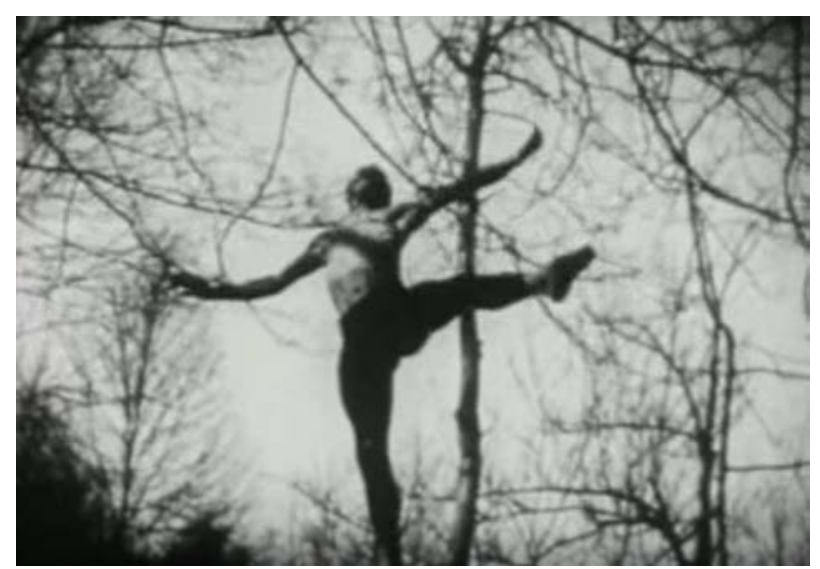

Figure 2: Deren, Maya. A Still from A Study in Choreography for Camera, 1945

\subsubsection{Systematic Process as Creativity}

Among science's procedure Deren appreciated the most its systematic way of thinking. Borrowing it, she tried to fulfil the accuracy and consistency of her perception.

In her notebook Deren defined a state of a steam engine and that of a human being with variables. For instance, she explained that a steam engine is "either be all there or not function at all" whereas a human being "becomes functioning by functioning", and that the change or evolution of the engine is constant whereas that of human is developmental (Deren 1947). By analysing a machine and human with the same standards, Deren got rid of any uncertain and unknown element in her creation.

These distinctions are reflected in $A$ Study $i n$ Choreography for Camera; the analysis on a steam engine can be considered equivalent onto a camera. For example, this film consists of a succession of different places or scenes with clear cuts. This reflects that a camera is "either be all there or not function at all." Meanwhile, for the whole duration of each scene a dancer keeps moving and progressing. This reflects that a dancer "becomes functioning by functioning." In this way Deren was able to achieve the clarity and simplicity of her film.

\subsubsection{Camera like the Body}

Manifested in a theoretical and notional way as the previous, Deren's embrace of science was also manifested in a physical and actual way. She considered a camera like the body:

"[...] my impulses and reactions towards the film translated themselves into muscular impulses and so to the film directly, with no machines - buttons, switches, etc. - between me and the film. All this seemed for me very important, [...]

I think one must at least begin with the body feeling. Once established, we understand each other and can work better together, separately."

$$
\text { Deren (1947, p.21-22) }
$$

This note shows that Deren perceived a camera as if there were no mechanical boundary between herself and the camera. It was because her mental embrace of science intervened her physical contact with a camera, a machine. It is not rare that artists project their views of science and technology onto a camera, a machine of perception, rather than the other machines. Dziga Vertov, a Russian Soviet filmmaker, is already known for his film Man with a Movie Camera (1929) where the artist's reverence of technology was projected on a camera.

As considered a camera like the body, Deren often held the camera without a tripod. Already equipped with the language of film, she followed her muscular impulses towards the tension between the camera and dancer. It is well manifested at the halfway point of this three-minute film. The dancer moved across the museum gallery, and Deren with a camera continuously and smoothly followed in order to film the dancer's both spatial and detailed movements affecting perception of the museum space. That is, the dancer danced with 'Deren with a camera.' These sensitive progressions were attributed to Deren's adoption of a camera like the body.

\subsection{Summary}

New technology engaged in Deren's synthesis was systematic process that had given science triumph in the war and post-WWII periods. Her embrace of this new technology contradicted and transformed her technophobia that had been caused by the war. In the course of this transformation her use of the systematic method to observe the world as well as her adoption of a camera like the body were evident. In such the artist's mind, which had been naturally or structurally developed during her life, 
the cultural evolution was originated. In other words "a special viewpoint leaving 'the rest" did not concern the artist, but "the 'World-itself'."

\section{CONCLUSION}

This paper has explored how to create a synthesis of art and new technology. By referring to Hegelian Dialectics it has compared two cases, Burnham's Systems Art and Deren's art. Burnham's idea of art as a communicator of the technological system was failed to be a synthesis because the relation of art and new technology was separable. On the contrary Deren's unseparated technophile and technophobic mind, which was her embrace of science in the post-WWII environment, pushed the artist towards evolving the meaning of the new technology at the time. This clearly shows that art and new technology as unseparatedness can only be successful to be a synthesis, inhering evolution.

At the very core of this paper was the researcher's endeavour to establish grounds for questioning on roles of art with regard to structuring meanings of newly developed and/or developing technology. To end it further questions its readers, being with this fundamental sense, about whether new technology has been an element or inspiration in his own art, and the reason for it.

\section{REFERENCES}

Burnham, Jack. (1980) Art and Technology: The Panacea that Failed. The Myths of Information: Technology and $P$ ostindustrial $C$ ulture, ed. Kathleen M. Woodward. Madison, WI: Coda Press.

Burnham, Jack. (1968) Systems Esthetics. Artforum vol. 7 no. 1.

Deren, Maya. (1946) An Anagram of Ideas on art, form and $f$ ilm. Yonkers, New York: Alicat Book Shop Press.

Deren, Maya. (1947) From the Notebook of Maya Deren, 1947. October 14. 21-46.

Deren, Maya, dir. (1945) A Study in Choreography for $C$ amera. Independent Filmmaking in United States. 16mm Film (Black and White, Silent), 3 min.
Diekmann, Katherine. (1985) Electra Myths: Video, Modernism, Postmodernism. Art Journal 45, no. 3, 195-203.

Haacke, Hans. (1968) Photoelectric $V$ iewercontrolled Coordinate System. Various dimensions.

Hegel, Georg Wilhelm Friedrigh. (1954) The Philosophy of Hegel. New York: Modern Library.

Julia, Noordegraaf, Saba Cosetta G., Le Maître Barbara, and Hediger Vinzenz, ed. (2013) Technological Platforms. In Preserving a nd Exhibiting Media A rt: $C$ hallenges and Perspectives. Amsterdam: Amsterdam University Press, 201-52.

Mueller, Gustav E. (1958) The Hegel Legend of "Thesis-Antithesis-Synthesis." Journal of $t$ he History of Ideas 19, no. 3, 411-14.

Neiman, Catrina. (1980) An Introduction to the Notebook of Maya Deren, 1947. October 14. 315. 
Pontus Hulten, Karl, ed. (1968) The Machine as Seen at the End of the Mechanical Age. New York: MoMA. Exhibition Catalogue.

Kramer, Hilton. (1982) The Modern Movement on the Eve of the Second World War. The American Scholar 51, no. 2, 219-28.

Reichardt, Jasia. (1970) Cybernetic S erendipity: The $C$ omputer and $t$ he Arts. London: Studio International.

Skrebowski, Luke. (2008) All Systems Go: Recovering Hans Haacke's Systems Art, Grey Room, no. 30. 54-83.

Turvey, Malcolm. (1999) Can the Camera See? Mimesis in "Man with a Movie Camera". October 89. 25-50.

Vertov, Dziga, dir. (1929) Man with a Movie Camera. Ukraine: VUFKU, 1929. 16mm Film, $68 \mathrm{~min}$. 